\title{
Downregulation of miR-205 is associated with glioblastoma cell migration, invasion, and the epithelial-mesenchymal transition, by targeting ZEB1 via the Akt/mTOR signaling pathway
}

\author{
WEI CHEN ${ }^{1,2^{*}}$, KUAN-KEI KONG ${ }^{1,2^{*}}$, XIN-KE XU ${ }^{1}$, CHENG CHEN $^{1}$, HUI LI $^{3}$, FANG-YU WANG ${ }^{1}$, \\ XIAO-FANG PENG ${ }^{1}$, ZHAN ZHANG ${ }^{1}$, PING LI ${ }^{1}$, JUN-LIANG LI ${ }^{1,2}$ and FANG-CHENG LI ${ }^{1,2}$ \\ ${ }^{1}$ Department of Neurosurgery, Institute of Pediatrics, Guangzhou Women and Children's Medical Center, \\ Guangzhou, Guangdong 510623; ${ }^{2}$ Department of Neurosurgery, Sun Yat-Sen Memorial Hospital, \\ Sun Yat-Sen University, Guangzhou, Guangdong 510120; ${ }^{3}$ Department of Respiratory Medicine, \\ The First People's Hospital of Foshan, Foshan, Guangdong 528000, P.R. China
}

Received March 27, 2017; Accepted September 4, 2017

DOI: 10.3892/ijo.2017.4217

\begin{abstract}
Glioblastoma (GBM) is the most common type of malignant brain tumor. In spite of recent advancements in surgical techniques, chemotherapy, and radiation therapy, patients with GBM often face a dire prognosis. MicroRNAs have been shown to modulate the aggressiveness of various cancers, and have emerged as possible therapeutic agents for the management of GBM. miR-205 is dysregulated in glioma and act as a prognostic indicator. However, the role of miR-205 in the development of GBM has not been elucidated. To better understand the pathogenesis of GBM, we examine the biological significance and molecular mechanisms of miR-205 in GBM cells. Zinc finger E-box binding homeobox 1 (ZEB1) has been shown to regulate the epithelial-mesenchymal transition (EMT), which is strongly associated with GBM malignancy. In the present study, we show miR-205 expression is reduced in GBM tissues and cell lines, and ZEB1 expression is inversely correlated with miR-205 expression. We also show ZEB1 is a downstream target of miR-205 and the Akt/mTOR signaling pathway is activated when miR-205 interacts with ZEB1. Increased activity of miR-205 in GBM
\end{abstract}

Correspondence to: Dr Fang-Cheng $\mathrm{Li}$ or Dr Jun-Liang Li, Department of Neurosurgery, Institute of Pediatrics, Guangzhou Women and Children's Medical Center, 9 Jinsui Road, Guangzhou, Guangdong 510623, P.R. China

E-mail: sjwklfc@126.com

E-mail: junliangli@aliyun.com

*Contributed equally

Abbreviations: GBM, glioblastoma; miRNAs, microRNAs; ZEB1, zinc finger E-box binding homeobox 1; EMT, epithelial-mesenchymal transition

Key words: glioblastoma, miRNA, ZEB1, epithelial-mesenchymal transition, migration, invasion cells significantly inhibits migration and invasion, and prevents EMT. Furthermore, overexpression of ZEB1 partially abolishes these inhibitory effects of miR-205. We show that miR-205 negatively regulates the expression of ZEB1 in GBM, inhibits cell migration and invasion, and prevents EMT, at least in part through the inhibition of the activation of the Akt/mTOR signaling pathway. Our results indicate miR-205 may be an efficacious therapeutic agent in the treatment of GBM.

\section{Introduction}

Glioblastoma (GBM), the most malignant form of glioma, is highly aggressive, and most patients diagnosed with this form of cancer often quickly succumb to the disease outcome (1). Despite the introduction of several modern therapeutic methods, including surgical resection, radiation therapy, and chemotherapy, the median survival time of patients diagnosed with GBM is only 14.6 months, with a 2 -year survival rate of only $26 \%(2,3)$. Therefore, a better understanding of the molecular and cellular changes that occur in GBM cells is essential to identify effective therapeutic targets for the treatment of GBM.

MicroRNAs (miRNAs) regulate the expression of their target mRNAs via partial or complete complementarity to the 3' untranslated region (UTR) of their target gene (4), and have been shown to play a critical role in tumor pathogenesis $(5,6)$. Studies have shown that some miRNAs have tumor suppressive functions, and many are aberrantly expressed in variety of cancers (7). Furthermore, several miRNAs have been shown to be involved in glioblastoma tumorigenesis by targeting oncogenes and tumor suppressor genes (8-10). For example, miR-204 has been shown to suppress glioma cell proliferation, migration, and invasion via the inhibition of activating transcription factor (11), and miR-92b-I has been reported to inhibit proliferation, invasion, and migration, and to stimulate apoptosis of glioma cells via the regulation of the PTEN/Akt signaling pathway (12). Another study showed that miR-423-5p functions as a tumor suppresser in glioma tissues by targeting the inhibitor of growth 4 gene (13). Recently, several studies 
have reported that miR-205 is dysregulated in clinical samples from solid tumors and glioma cell lines (14-17). However, to date, the role of miR-205 in the development of GBM has not been elucidated.

The epithelial-mesenchymal transition (EMT) is a vital morphogenic process during embryonic development, and is crucial for epithelial cancer cell acquisition of an invasive phenotype (18). EMT is regulated by several transcription factors, including zinc finger E-box binding homeobox 1 (ZEB1) and Twist1, which have been shown to be transcriptional repressors of E-cadherin (19). ZEB1 plays a key role in the regulation of tumor metastasis by inducing EMT (20). Furthermore, studies have indicated that ZEB1 is upregulated in GBM cells and may repress genes involved in cancer cell adhesion and polarity (21). Therefore, inhibition of ZEB1 expression may be beneficial for the therapeutic management of GBM.

In this study, we show that miR-205 expression is reduced in GBM tissues and cell lines, and that miR-205 expression is negatively associated with ZEB1 expression in GBM tissues. Furthermore, we show miR-205 downregulates ZEB1, causing suppression of GBM cell migration and invasion, and reverses EMT via the Akt/mTOR signaling pathway. These findings elucidate the role of miR-205 in GBM, and suggest that miR-205 may be an effective therapeutic target for the treatment of patients with GBM.

\section{Materials and methods}

Tissue specimens. Tissue specimens from 76 GBM and corresponding normal brain tissues were obtained from the Guangzhou Women and Children's Medical Center and Sun Yat-Sen Memorial Hospital between January 2013 and October 2015. Each sample was frozen in liquid nitrogen within $2 \mathrm{~h}$ of extraction. The medical history of each patient was recorded as shown in Table I. GBM diagnosis was made according to the revised WHO classification system (22). Patients who had received treatment, including chemotherapy and radiation therapy, before surgery, were excluded. All experiments were performed in accordance with the guidelines approved by the Ethics Committee of Sun YatSen Memorial Hospital, and informed consent was obtained from each patient.

Cell culture and transfection. The human glial HEB and glioblastoma cell lines U87MG, SHG-44, U251, and A172 were maintained in Dulbecco's modified Eagle's medium (DMEM) with low glucose, supplemented with $10 \%$ fetal bovine serum (Gibco, MD, USA). Cells were incubated at $37^{\circ} \mathrm{C}$ with $5 \% \mathrm{CO}_{2}$. Control RNA mimics and miR-205 mimics were obtained from Ribobio (Guangzhou, China), and transfected into cells at a working concentration of $50 \mathrm{nM}$ using Lipofectamine 2000 reagent (Invitrogen, Carlsbad, CA, USA) according to the manufacturer's instructions.

ZEBl gene expression rescue assay. The full length ZEB1 gene open reading frame (ORF) was amplified via PCR and cloned into pcDNA-3.1 (Invitrogen) to generate a pcDNA-3.1+ZEB1 construct (hereinafter, ZEB1). The empty pcDNA-3.1 served as the control (hereinafter, vector). SHG-44 and A172 cells were transfected with the miR-205 mimic (50 $\mathrm{nM})$, in 6-well plates, followed by co-transfection with $2.0 \mu \mathrm{g}$ of either pcDNA-3.1+ZEB1 or control vector for $48 \mathrm{~h}$.

RNA extraction and quantitative real-time PCR ( $q R T-P C R)$. Total RNA was extracted using TRIzol reagent (Invitrogen) according to the manufacturer's protocol, and reversetranscription was conducted using PrimeScript ${ }^{\mathrm{TM}}$ RT-PCR kit (Takara, Otsu, Shiga, Japan). qRT-PCR was performed to quantify expression levels using the SYBR Green PCR Master mix (Applied Biosystems, Foster City, CA, USA) according to the manufacturer's instructions. qRT-PCR was performed at $94^{\circ} \mathrm{C}$ for $2 \mathrm{~min}$ followed by 40 cycles at $94^{\circ} \mathrm{C}$ for $10 \mathrm{sec}$, $60^{\circ} \mathrm{C}$ for $1 \mathrm{~min}$, and $30 \mathrm{sec}$ at $72^{\circ} \mathrm{C}$ on an ABI PRISM 7500 Real-Time PCR system (Applied Biosystems). Expression of mature miR-205 was assayed using the Bulge-Loop ${ }^{\mathrm{TM}}$ miRNA qRT-PCR Primer Set and the miRNA qRT-PCR Control Primer Set (RiboBio, Guangdong, China). GAPDH and U6 were used as internal controls. All sequences used are shown in Table II. Each reaction was performed in triplicate. Relative quantification of gene expression levels was expressed as fold change, normalized against internal controls, using the $\Delta \Delta \mathrm{Cq}$ method. Each sample was detected in triplicate.

Western blotting. Total protein was extracted from cells using $1 \%$ RIPA lysis buffer (Beyotime, Jiangsu, China), and the BCA method was used for protein quantitation. Equal concentrations of protein were separated by SDS-PAGE, transferred onto PVDF membranes, and probed with ZEB1, mTOR, phospho-mTOR (Abcam, MA, USA), Akt, phospho-Akt, E-cadherin, N-cadherin, vimentin (Cell Signaling Technology, Beverly, MA, USA) and GAPDH (Abcam) antibodies overnight at $4^{\circ} \mathrm{C}$. The membranes were incubated with horseradish peroxidase (HRP)-conjugated secondary antibodies (Abcam) for $2 \mathrm{~h}$. Immunocomplexes were visualized using the ECL detection reagent (Beyotime) and the intensities of the signals were quantified using ImageJ software 6.0.

Cell migration and invasion assay. Approximately $10^{6}$ cells were seeded into each well of 6-well plates. A cell scratch spatula was used to scratch the cell after transfection. Plates were washed using warmed phosphate-buffered saline three times to remove cellular debris, and the cells were incubated at $37^{\circ} \mathrm{C}$ for $48 \mathrm{~h}$, examined and photographed under a microscope (Olympus Corp., Tokyo, Japan) 0 and 48 h after wounding. Each cell condition was assayed in triplicate.

Transwell chambers (8- $\mu \mathrm{m}$ pore size; Millipore, Billerica, MA, USA) coated with Matrigel (BD Biosciences, San Jose, CA, USA) were used for the invasion assays. Following transfection, cells were seeded onto the upper wells, and $500 \mu \mathrm{l}$ DMEM containing $10 \%$ fetal bovine serum (FBS) was used as a chemoattractant in the lower chambers. The cells were allowed to migrate for $24 \mathrm{~h}$, the Matrigel and the cells in the upper surface were removed, and the cells that had migrated to the lower surface were fixed in $4 \%$ paraformaldehyde and stained with $0.1 \%$ crystal violet (Sigma, St. Louis, MO, USA). The number of invaded cells were counted under a light microscope (Axiovert 200 inverted microscope; Zeiss, Germany) in five fields, and presented as the average number of cells per field of view. 
Table I. Characteristics of glioma patients.

\begin{tabular}{lc}
\hline Characteristics & Patients $(\mathrm{n}=76)$ \\
\hline Median age (years) & 50.2 \\
Range & $34-75$ \\
Male & $39(51.3 \%)$ \\
Smoking status & \\
Ever and current & $23(30.3 \%)$ \\
Never & $53(69.7 \%)$ \\
Alcohol consumption & \\
Ever and current & $25(32.9 \%)$ \\
Never & $51(67.1 \%)$ \\
KPS score & \\
$\geq 70$ & $29(38.2 \%)$ \\
$<70$ & $51(61.8 \%)$ \\
Extent of resection & \\
Gross total resection & $53(69.7 \%)$ \\
Subtotal resection & $23(30.3 \%)$ \\
WHO & $29(38.2 \%)$ \\
I+II & $47(61.8 \%)$ \\
III+IV & \\
\hline
\end{tabular}

Luciferase reporter assay. Potential targets of miR-205 were predicted using miRbase, and finally the putative complementary sequence of miR-205 was identified in the 3'UTR of ZEB-1 mRNA. Luciferase reporter vectors were constructed using the full 3'UTR of ZEB-1 and inserted into the pEZX-MT01 vector (GeneCopia, Labomics S.A, Nivelles, Belgium). Empty vectors were used as a negative control. Renilla luciferase, encoded by the same vector, served as an internal control. Each luciferase reporter construct, including the Luc+miR205, Luc+ZEB1 3'UTR, and negative control vectors, was co-transfected into SHG-44 cells and A172 cells using Lipofectamine 2000 (Invitrogen). After $24 \mathrm{~h}$ of incubation, the cells were re-seeded in 96-well plates and then Firefly and Renilla luciferase activities were determined using Luc-Pair ${ }^{\mathrm{TM}}$ miR Luciferase assay kits (GeneCopia) according to the manufacturer's instructions. All transfection experiments were performed in triplicate and repeated three times.

Immunofluorescence analysis. To analyze immunofluorescence, SHG-44 and A172 cells were transfected with miRNA-NC or miRNA-205 mimics for $48 \mathrm{~h}$ and cultured on circular coverslips (BD Biosciences) in 6-well plates, then washed and fixed with $4 \%$ paraformaldehyde for $15 \mathrm{~min}$. The cells were then permeabilized with $0.1 \%$ Triton $\mathrm{X}$ for $5 \mathrm{~min}$ and blocked for 30 min with $3 \%$ bovine serum albumin (BSA)-PBS at room temperature. The cells were incubated overnight at $4^{\circ} \mathrm{C}$ with anti-ZEB1 primary antibodies, then incubated with a fluorescent secondary antibody for $1 \mathrm{~h}$ at room temperature. To visualize the nuclei, the wells were stained with DAPI (Sigma) for $5 \mathrm{~min}$. Fluorescent images (at x200 magnification) were acquired using a fluorescence inverted microscope (Olympus) and images were processed with Image-ProPlus 6.0 (Media Cybernetics, USA).
Table II. The forward and reverse primers for real-time PCR.

\begin{tabular}{|c|c|c|}
\hline Name & & Sequence \\
\hline \multirow[t]{2}{*}{ Hsa-miR-205 } & Forward & GTGACCAACATACCACCGG \\
\hline & Reverse & TGGTGTCGTGGAGTCG \\
\hline \multirow[t]{2}{*}{ ZEB1 } & Forward & CAGCTTGATACCTGTGAATGGG \\
\hline & Reverse & TATCTGTGGTCGTGTGGGACT \\
\hline \multirow[t]{2}{*}{ E-cadherin } & Forward & AAAGGCCCATTTCCTAAAAACC \\
\hline & Reverse & TGCGTTCTCTATCCAGAGGCT \\
\hline \multirow[t]{2}{*}{ N-cadherin } & Forward & AGCCAACCTTAACTGAGGAGT \\
\hline & Reverse & GGCAAGTTGATTGGAGGGATG \\
\hline \multirow[t]{2}{*}{ Vimentin } & Forward & AGTCCACTGAGTACCGGAGAC \\
\hline & Reverse & CATTTCACGCATCTGGCGTTC \\
\hline \multirow[t]{2}{*}{ U6 } & Forward & CTCGCTTCGGCAGCACA \\
\hline & Reverse & AACGCTTCACGAATTTGCGT \\
\hline \multirow[t]{2}{*}{ GAPDH } & Forward & ACAACTTTGGTATCGTGGAAGG \\
\hline & Reverse & GCCATCACGCCACAGTTTC \\
\hline
\end{tabular}

Statistical analysis. Data were expressed as the mean \pm standard deviation (SD). Student's t-test was used to compare differences between two groups. One-way analysis of variance (ANOVA) was used to compare the differences between more than two groups, and significance was determined using the LSD t-test. Pearson correlation was used to analyze the relationship between miR-205 and ZEB1 expression. A P-value of $<0.05$ was considered statistically significant. All statistical analyses were performed using SPSS 20.0 (SPSS, Inc., Chicago, IL, USA), and GraphPad Prism 6.0 (GraphPad Software, Inc., CA, USA) was used to generate graphs.

\section{Results}

miR-205 is downregulated in GBM tissues and cell lines. Previous studies have shown miR-205 expression is reduced in GBM tissues and cell lines $(14,15)$. Therefore, we investigated miR-205 expression, via qRT-PCR, from surgically excised specimens. Our results showed that miR-205 was significantly downregulated in GBM tissues, as compared to the corresponding non-neoplastic tissues (Fig. 1A). Furthermore, we found miR-205 expression was also substantially decreased in several glioma cell lines, as compared to human glial HEB cells (Fig. 1B).

$m i R-205$ directly targets the 3 'UTR of ZEBI in GBM. To determine the downstream targets of miR-205 and its role in GBM, we queried candidate target genes from the human microRNA database, and found ZEB1 was a putative target of miR-205. Therefore, we decided to investigate ZEB1 expression in GBM tissues and glioma cell lines. As shown in Fig. 2A, the levels of ZEB1 in GMB tissues were lower than those in the non-tumor tissues. A subsequent correlation analysis found ZEB1 was negatively correlated with miR-205 expression (Fig. 2B). Our qRT-PCR results showed that miR-205 expression in SHG-44 and A172 cells increased more than 130-fold in the miR-205 mimics group compared to miR-NC group (Fig. 3A and B). 

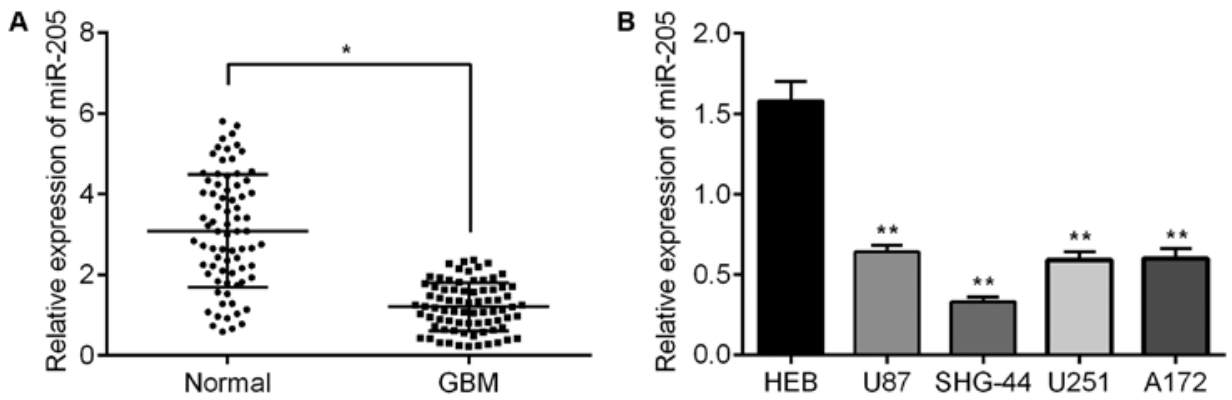

Figure 1. miR-205 is downregulated in glioblastoma tissues and cells. (A) miR-205 expression in glioblastoma tissues and corresponding non-tumor tissues. (B) miR-205 expression in human glial HEB cells and the glioblastoma cell lines U87MG, SHG-44, U251, and A172. "P<0.05 vs. normal group; ${ }^{* *} \mathrm{P}<0.05$ vs. HEB group.
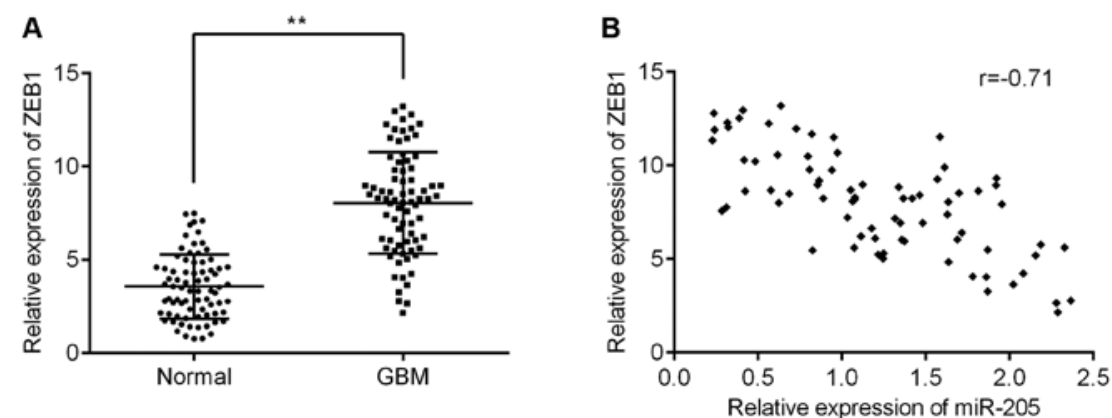

Figure 2. ZEB1 expression is negatively correlated with miR-205 in glioblastoma tissues. (A) ZEB1 expression in glioblastoma tissues and corresponding non-tumor tissues. (B) Relative expression of ZEB1 and miR-205, analyzed by Pearson correlation. ${ }^{* *} \mathrm{P}<0.01$ vs. normal group.
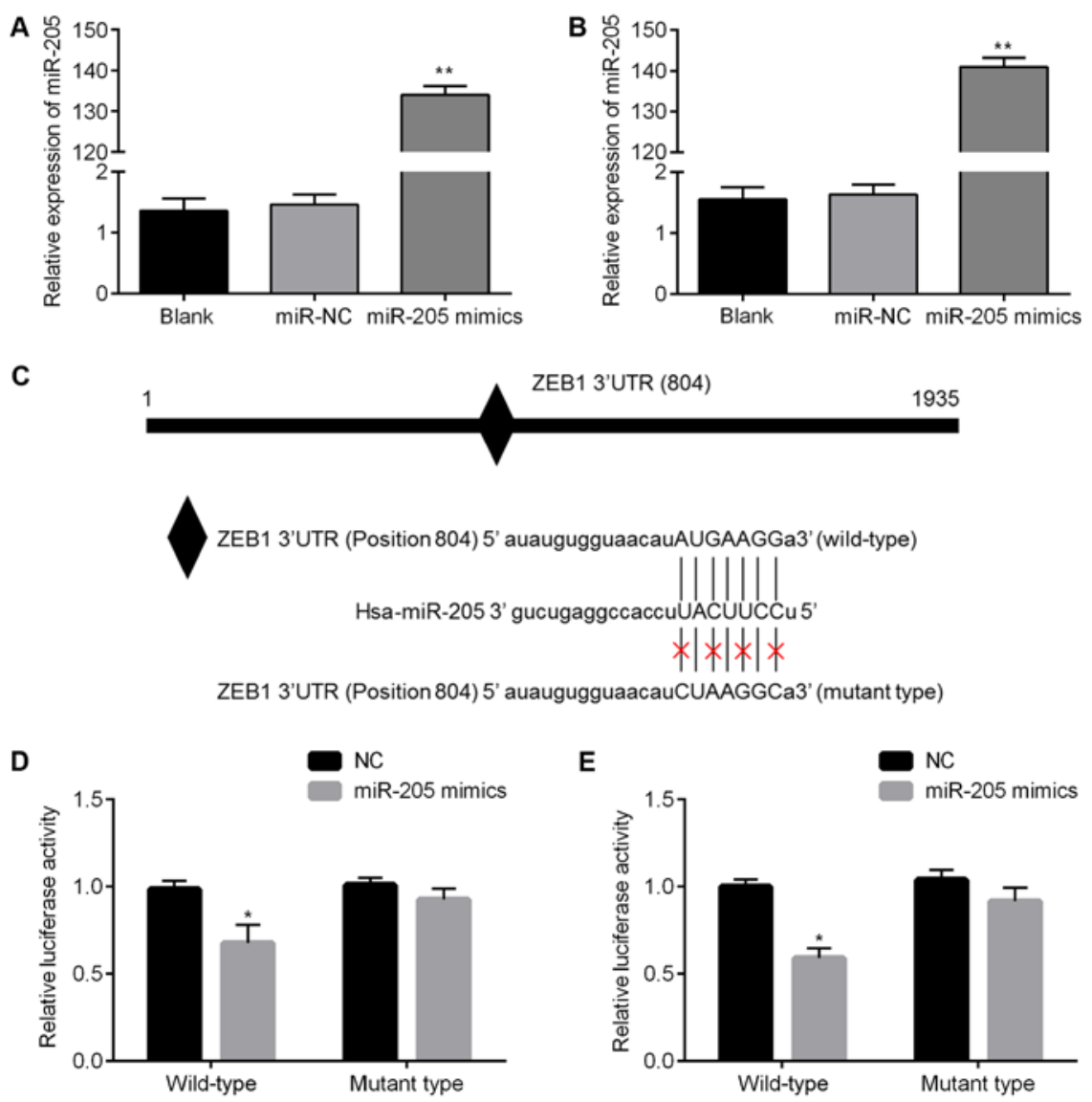

Figure 3. ZEB1 is a downstream target of miR-205, which directly binds to the 3'UTR of ZEB1. (A) Relative miR-205 expression in SHG-44 and (B) A172 cells transfected with miR-205 mimics or miR-NC mimics detected by qRT-PCR. (C) Putative target location of miR-205 in the 3'UTR of ZEB1 (804-810) as predicted on microRNA.org (http://www.microrna.org/microrna/getMirnaForm.do). Luciferase activity of (D) SHG-44 and (E) A172 cells transfected with plasmids carrying the wild-type or mutant 3 'UTR of ZEB1 following the binding of miR-205. ${ }^{*} \mathrm{P}<0.05,{ }^{* * *} \mathrm{P}<0.01$ vs. miR-NC group. 


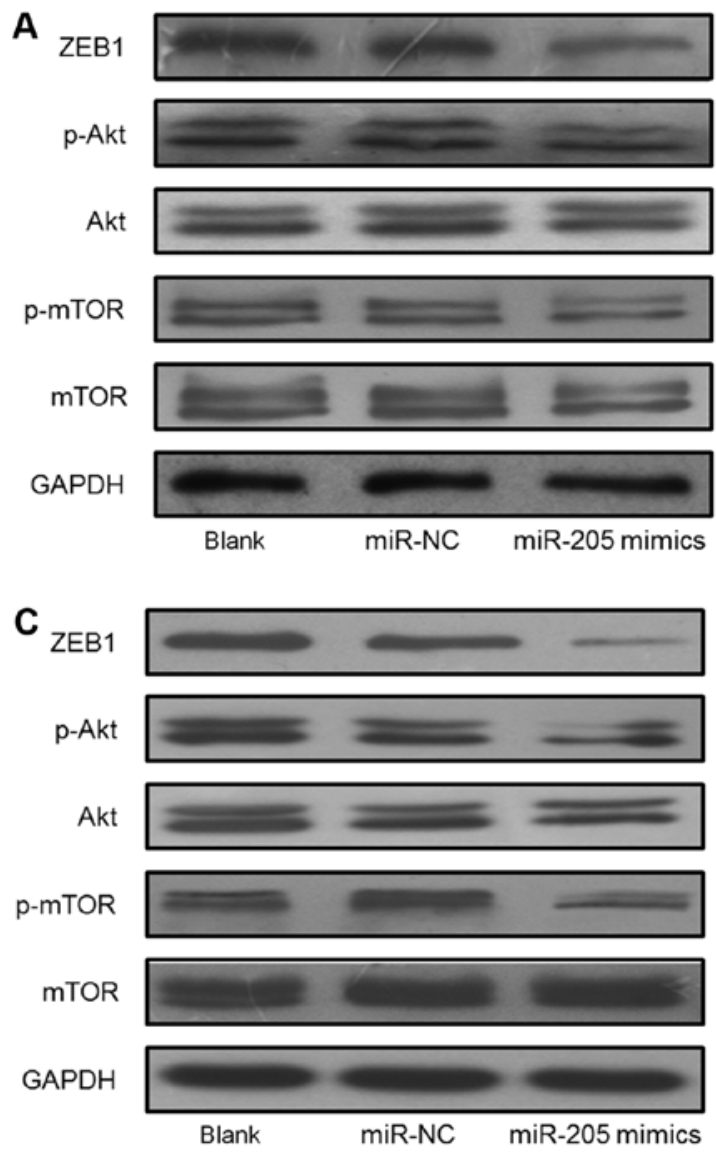

E
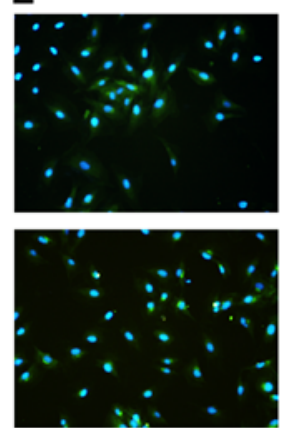

Blank
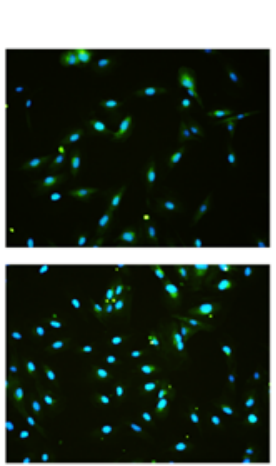

miR-NC

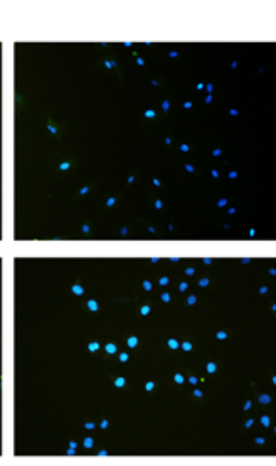

miR-205 mimics
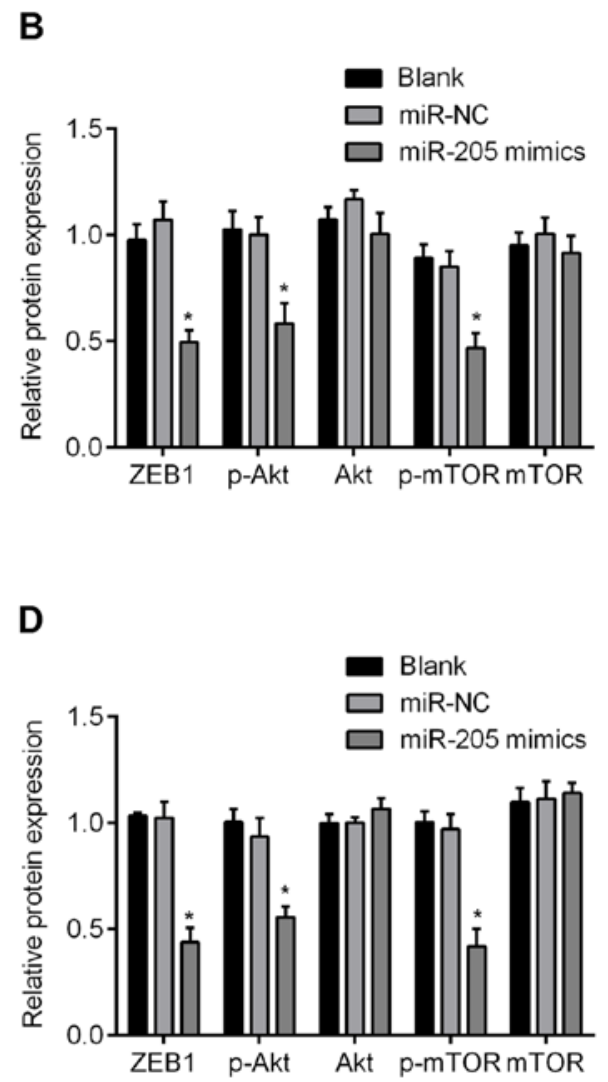

F

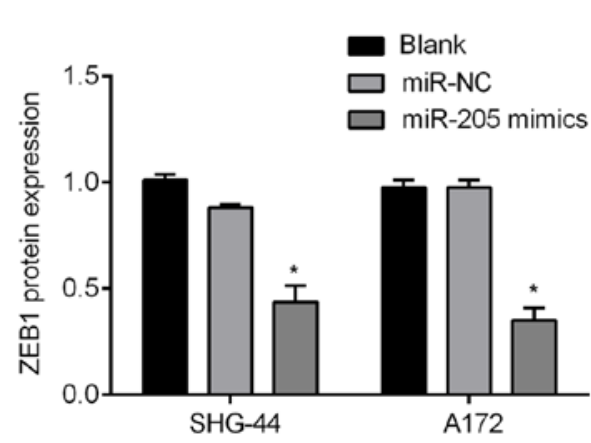

Figure 4. miR-205 regulates Akt/mTOR signaling pathways by targeting ZEB1. (A) SHG-44 and (C) A172 cells transfected with a miR-205 mimic or negative control mimics (miR-NC) showing total protein used to detect ZEB1, p-Akt, total-Akt, p-mTOR, total-mTOR, and GAPDH expression by western blotting. (B) SHG-44 and (D) A172 cell relative protein levels presented as mean \pm SD from three experiments. The asterisk indicates expression levels of ZEB1, p-Akt, and p-mTOR were significantly lower in the miR-205 mimic group than that in miR-NC group ( $\mathrm{P}<0.05)$. (E, F) SHG-44 (upper) or A172 cells (lower) stained for ZEB1 by immunofluorescence. Red, ZEB1; blue, DAPI nuclear staining.

Fig. 3C shows the putative position of the miR-205 target site in the 3'UTR of ZEB1 mRNA. To confirm these findings, we performed a luciferase assay, and found that in SHG-44 and A172 cells overexpression of miR-205 suppressed luciferase activity, while transfection of a scrambled sequence had no effect (Fig. 3D and E). These results suggest that miR-205 regulates ZEB1 expression by targeting its 3'UTR.

miR-205 regulates the Akt/mTOR signaling pathway by targeting ZEB1. In order to further elucidate the molecular mechanisms of miR-205 in GBM metastasis, we examined the downstream signaling pathways activated by ZEB1. We found ZEB1 protein expression in SHG-44 and A172 cells transfected with the miR-205 mimics were significantly inhibited, as detected by western blotting (Fig. 4A-D). Along with the decrease in ZEB1 levels, overexpression of miR-205 also inhibited p-Akt and p-mTOR expression levels, but had no effect on total Akt and mTOR expression levels (Fig. 4A-D). These results indicate that miR-205 regulates the Akt/mTOR signaling pathway by targeting ZEB1. We also performed immunofluorescent staining on SHG-44 and A172 cells transfected with miR-205 mimics or miR-NC mimics. As shown in Fig. 4E, the ZEB1 protein is expressed in the cytoplasm of the SHG-44 and A172 cells, and Fig. 4F shows its level is reduced in the miR-205 mimics group as compared with the miR-NC group, which corresponds with our western blotting results. 


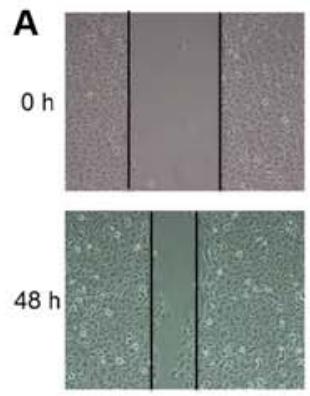

Blank
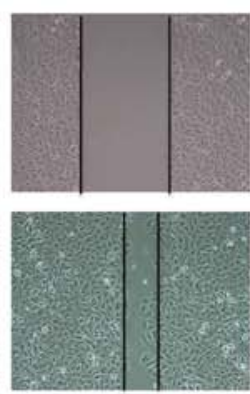

miR-NC
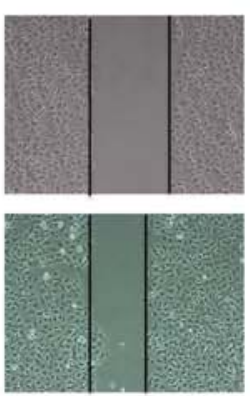

miR-205 mimics
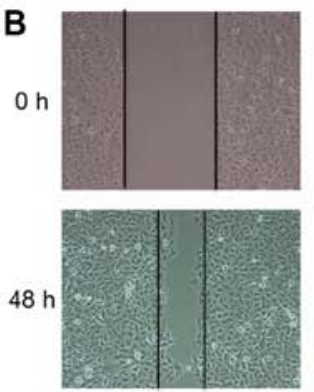

Blank
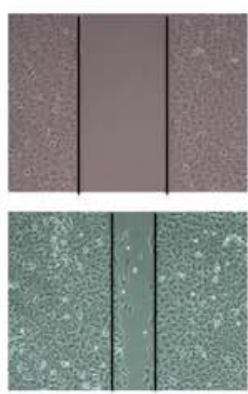

miR-NC
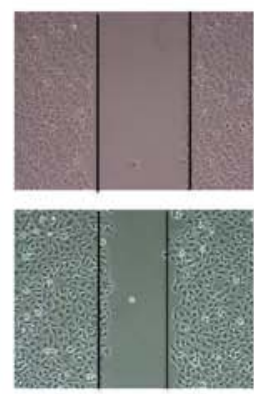

miR-205 mimics

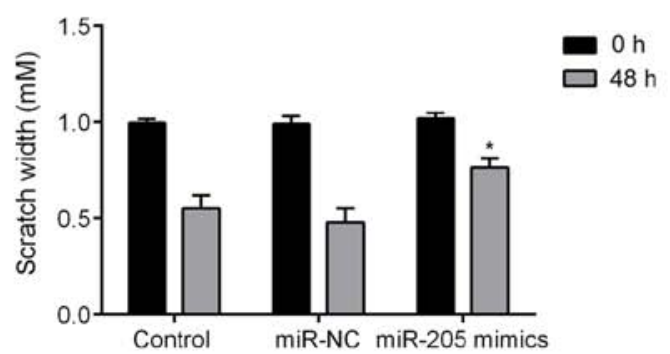

C

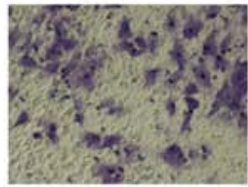

Blank

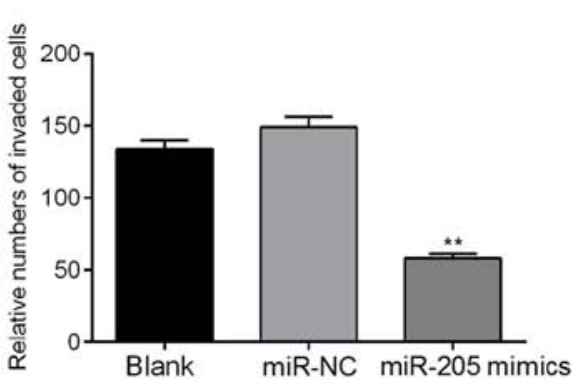

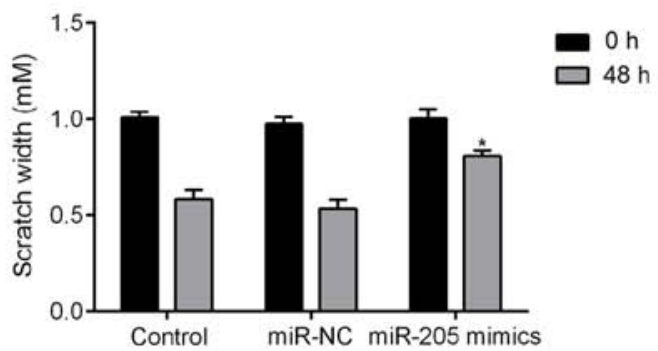

D

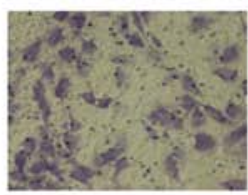

Blank

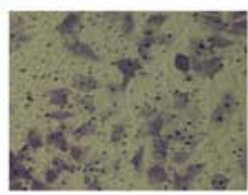

miR-NC

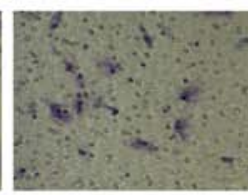

miR-205 mimics

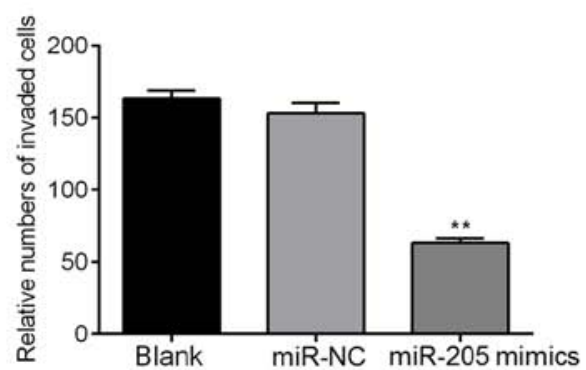

Figure 5. miR-205 inhibits the migration and invasion of glioma cells. (A) SHG-44 and (B) A172 cells transfected with miR-205 mimics or miR-NC subjected to wound-healing analysis. (C) SHG-44 and (D) A172 invaded cells stained with $0.1 \%$ crystal violet counted 48 h after transfection. The number of invaded cells was determined from three replicate wells and expressed as mean $\pm \mathrm{SD}$ (bottom). ${ }^{*} \mathrm{P}<0.05,{ }^{* *} \mathrm{P}<0.01 \mathrm{vs}$. miR-NC group.

miR-205 inhibits cell migration and invasion and reverses EMT in GBM. We also tested the effects of miR-205 on the migration and invasion properties of glioma cells. Our wound healing assay showed that the cell migration was suppressed when miR-205 was overexpressed in both SHG-44 and A172 cells (Fig. 5A and B). Furthermore, our Transwell invasion assay indicated that ectopic expression of miR-205 significantly inhibited the invasive response of both SHG-44 and A172 cells (Fig. 5C and D). To determine the regulatory effect of miR-205 on EMT, we performed qRT-PCR and western blot analyses. The E-cadherin mRNA expression level was markedly increased in the miR-205 mimics group, while $\mathrm{N}$-cadherin and vimentin were decreased in both SHG-44 and A172 cells (Fig. 6A and B). Consistent with the qRT-PCR results, E-cadherin, N-cadherin, and vimentin protein expression showed similar changes (Fig. 6C and D).

ZEBI is a key regulator of the tumor regulatory function of $m i R-205$. We performed a rescue assay to investigate if ZEB1 is involved in the miR-205-mediated regulation of glioma cells (23-25). Following transfection, the mRNA and protein levels of ZEB1 increased in glioma cells transfected with pcDNA-3.1+ZEB1 (Fig. 7). We also found an increase in the migratory ability of glioma cells transfected with the ZEB1 construct following treatment with the miR-205 mimics (Fig. 8A and B). In addition, upregulation of ZEB1 partially reversed the effects of miR-205 on cell invasion ability (Fig. 8C and D). Overexpression of ZEB1 inhibited E-cadherin expression and induced the expression of $\mathrm{N}$-cadherin and vimentin as detected by qRT-PCR (Fig. 9A and B) and western blotting (Fig. 9C and D). These data indicate that miR-205 inhibits cell migration and invasion, and reverses EMT by downregulating ZEB1 in GBM cells.

\section{Discussion}

MicroRNAs can be either upregulated or downregulated, and function as oncogenes or tumor suppressors depending on their target genes (26). Accumulating evidence reveals the vital role of miRNAs involved in processes such as 
A

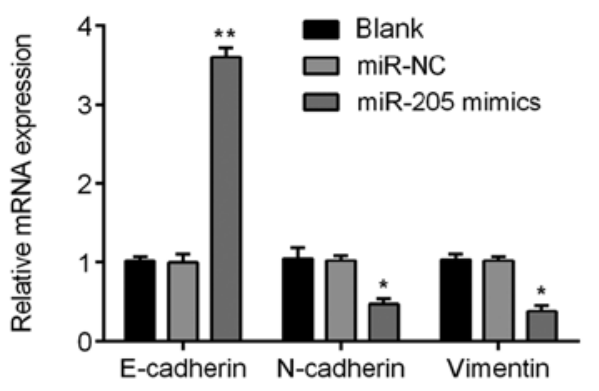

C

E-cadherin
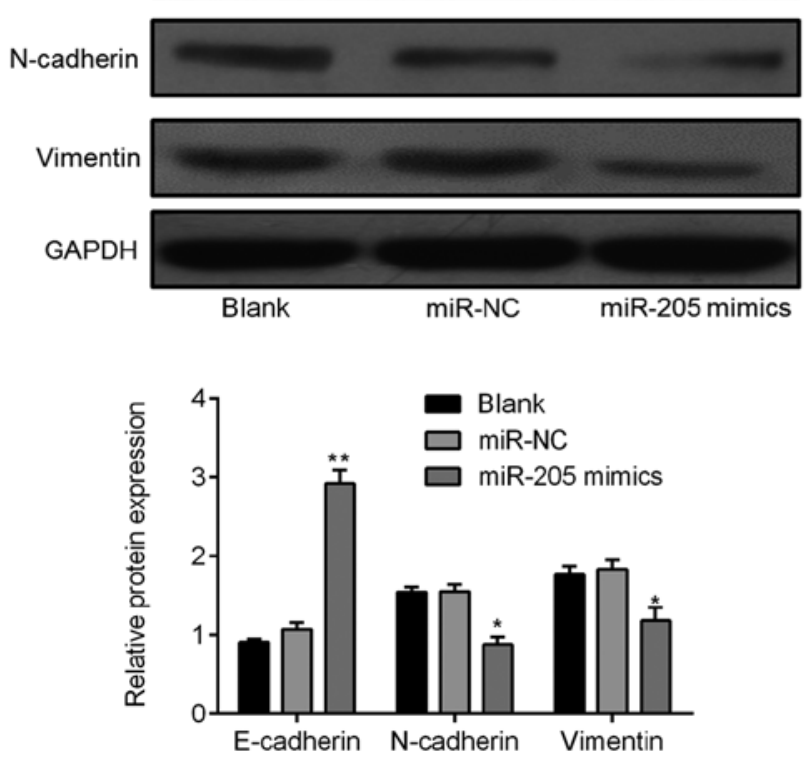

B

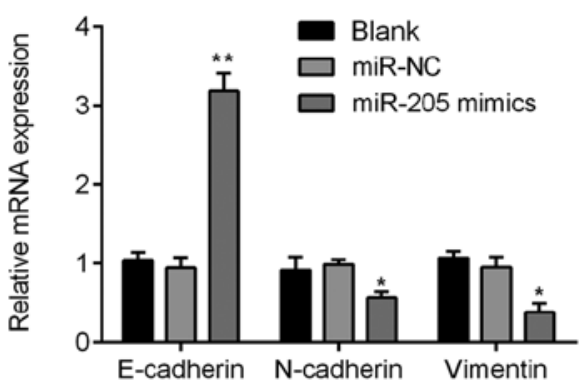

D
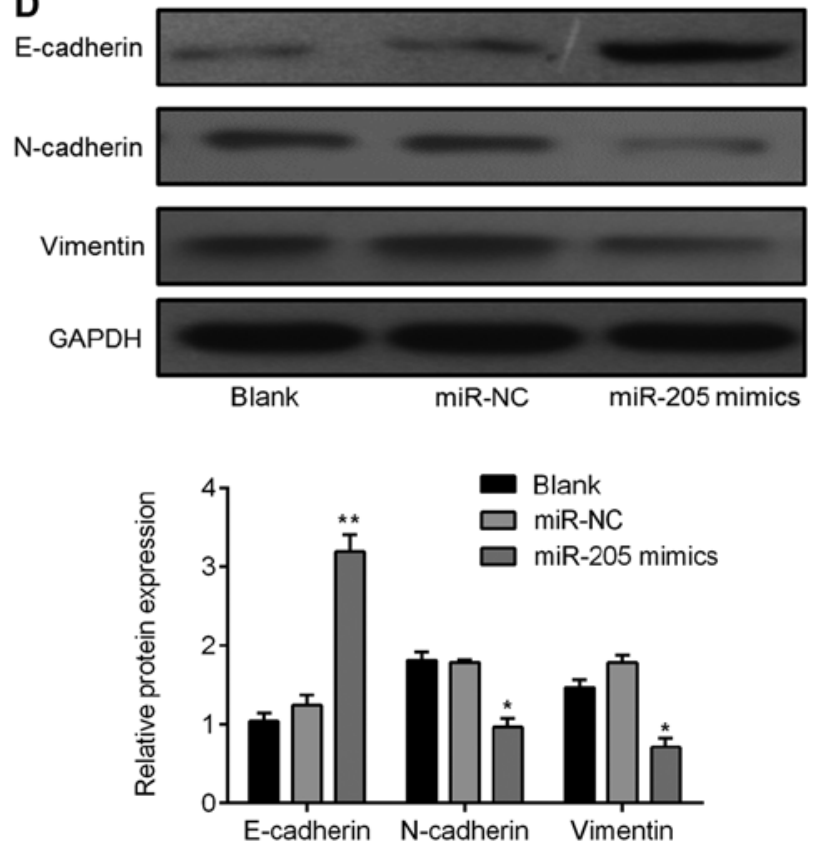

Figure 6. miR-205 regulates epithelial-mesenchymal transition (EMT) in glioma cells. (A) SHG-44 and (B) A172 cell expression levels of the EMT markers, E-cadherin, N-cadherin and vimentin in samples transfected with miR-205 mimics or miR-NC. (C) SHG-44 and (D) A172 cell: E-cadherin, N-cadherin and vimentin expression via western blotting following transfection. ${ }^{*} \mathrm{P}<0.05,{ }^{* *} \mathrm{P}<0.01$. vs. miR-NC group.
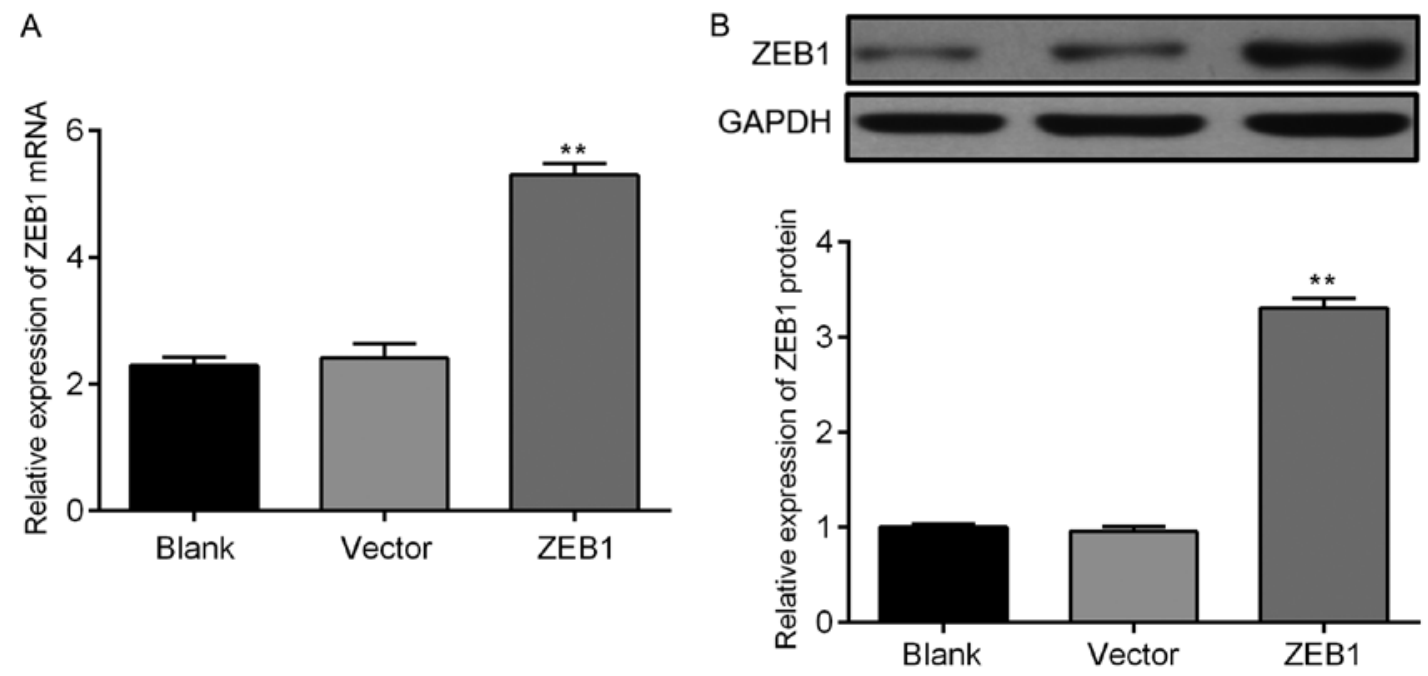

Figure 7. Upregulation of ZEB1 in glioma cells following plasmid transfection. (A) Alteration of ZEB1 mRNA expression in groups transfected with pcDNA-3.1+ZEB1 or pcDNA-3.1 constructs. (B) ZEB1 protein expression following transfection with a ZEB1-expressing plasmid. ${ }^{* *} \mathrm{P}<0.01$ vs. vector group.

proliferation and invasion and in prognosis of GBM (27-29). It is well established that ZEB1 is a powerful regulator of EMT, and numerous miRNAs have been reported to be either direct or indirect regulators of EMT (30-32).
In this study, we examined the function of miR-205 in malignant glioma cells. We showed that miR-205 expression is significantly decreased in GBM tissues and cell lines. We also found overexpression of miR-205 inhibits migration and 
A
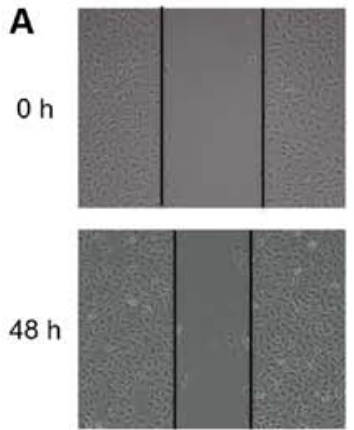

miR-205 mimics

+ Vector
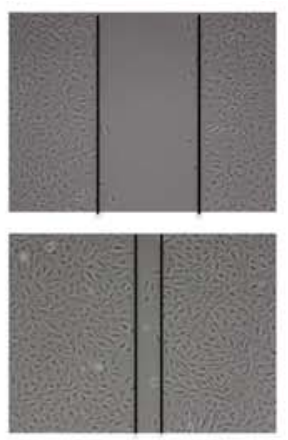

miR-205 mimics

+ ZEB1

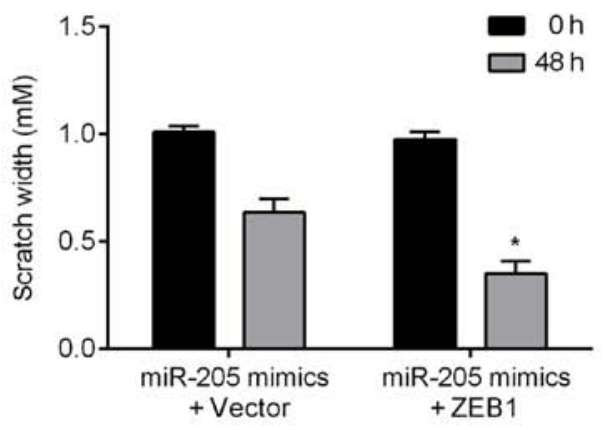

C

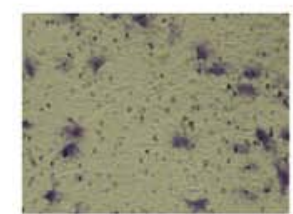

miR-205 mimics + Vector

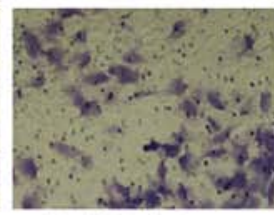

miR-205 mimics

+ ZEB1

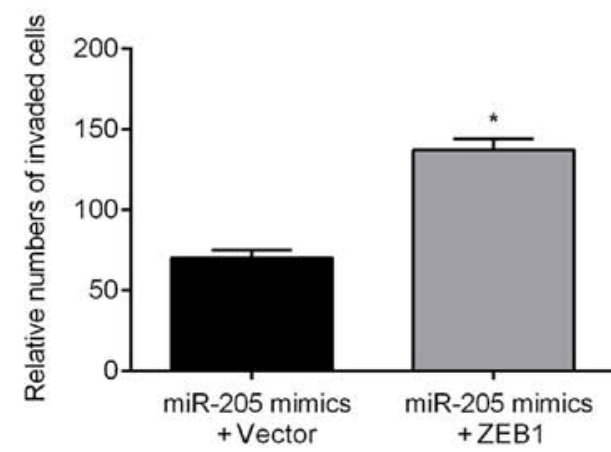

B

$\mathrm{Oh}$
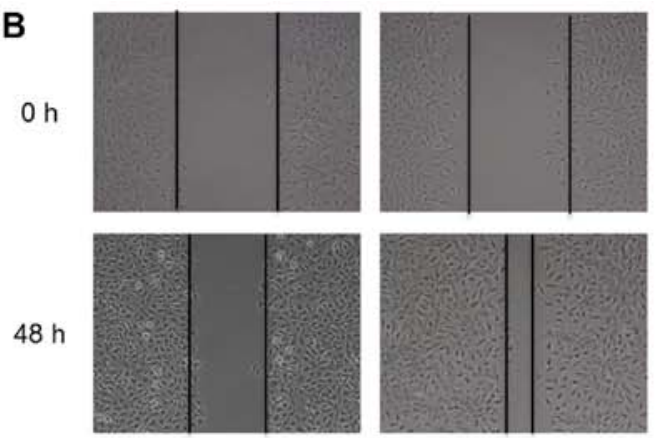

miR-205 mimics

+ Vector

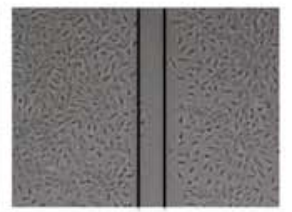

miR-205 mimics

+ ZEB1

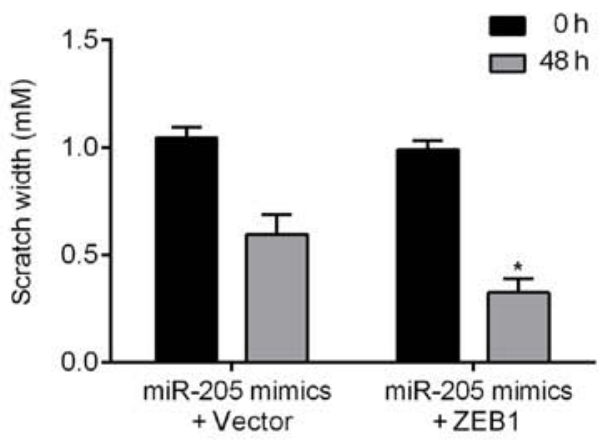

D

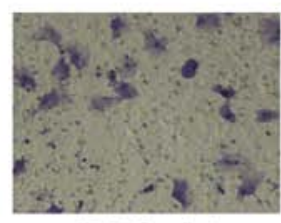

miR-205 mimics

+ Vector

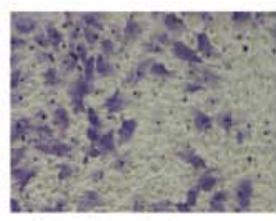

miR-205 mimics jics

+ ZEB1

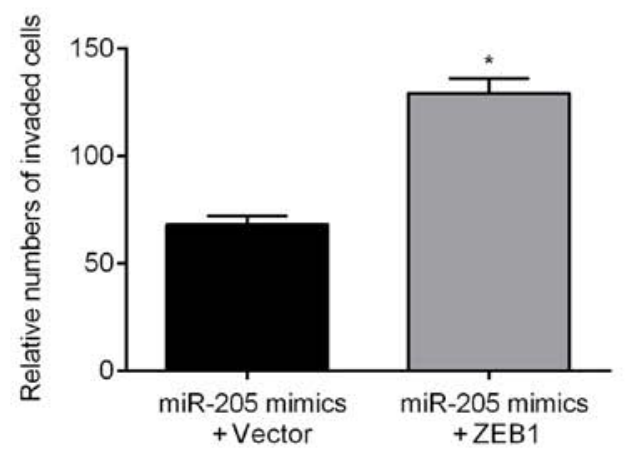

Figure 8. Enforced expression of ZEB1 partially abrogates miR-205 induced inhibitory effects. (A and B) Cell migration ability was assessed in SHG-44 or A172 in cells co-transfected with miR-205 mimics and ZEB1-expressing plasmid or empty vector. (C and D) Transwell assays of cell invasion. * $<<0.05$ vs. miR-205 mimics + vector group.

invasion, and reverses EMT in glioma cells (Figs. 5 and 6). To determine the potential mechanisms of miR-205 function, we identified downstream targets, and found the 3'UTR of ZEB1 contained a sequence complementary to miR-205 (Fig. 3). Furthermore, we found upregulation of ZEB1 could abolish the inhibitory effects of miR-205 in glioma cell lines (Figs. 8 and 9). These results suggest an underlying mechanism whereby miR-205 suppression might contribute to the malignancy of GBM.

Previous studies have demonstrated a relationship between miR-205 and metastasis in several cancers. miR-205 suppresses proliferation, migration, and invasion of osteosarcoma cells by binding to the 3'UTR of the vascular endothelial growth factor A gene (VEGFA) (33). Liu et al determined miRNA expression levels in samples of melanoma tissues and found significantly reduced miR-205 levels. Overexpression of miR-205 suppressed cell migration and proliferation in vitro and in vivo (17). In addition, miR-205 plays a crucial role in EMT as a silencer of the ZEB1/2 transcriptional repressor $(34,35)$. $\mathrm{Xu}$ et al previously indicated that miR-205 prevents EMT by targeting ZEB1 in gastric cancer cells, suggesting that miR-205 may be applied in the treatment of human gastric cancer (36). In the present study, we identified the loss of miR-205 in GBM tissues and cell lines, and the following experiments strongly 
A

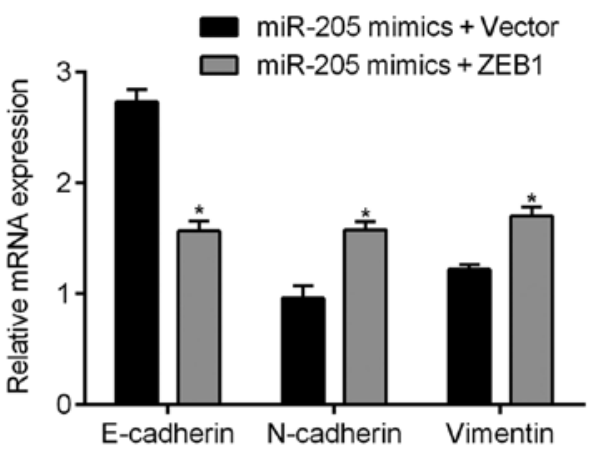

C

E-cadherin

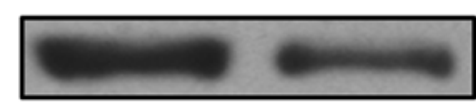

$\mathrm{N}$-cadherin

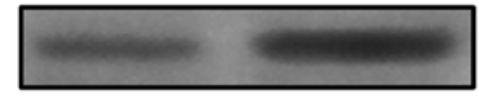

Vimentin

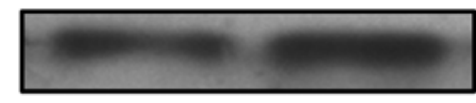

GAPDH
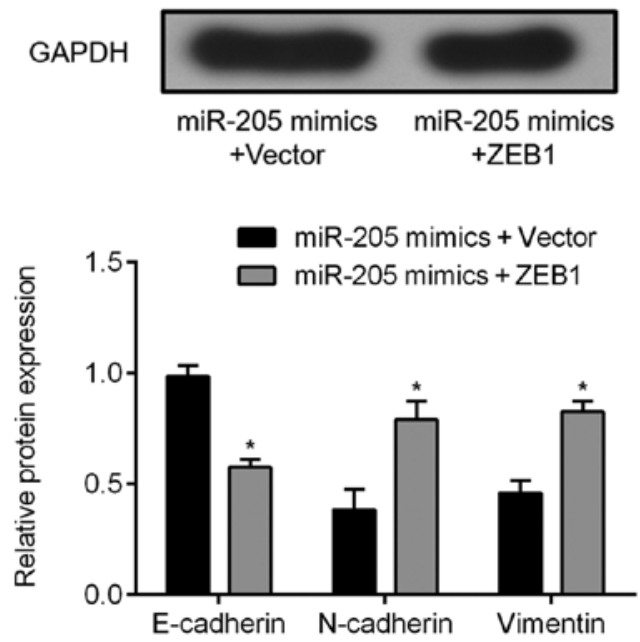

B

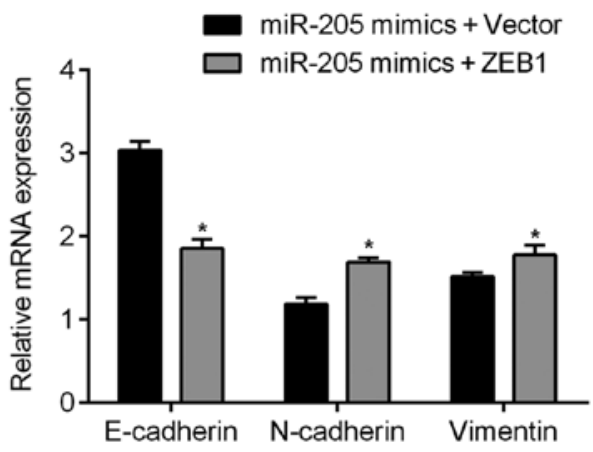

D

E-cadherin

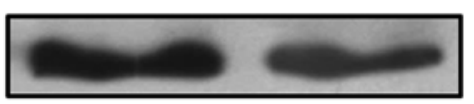

$\mathrm{N}$-cadherin

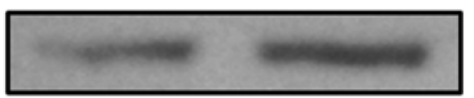

Vimentin

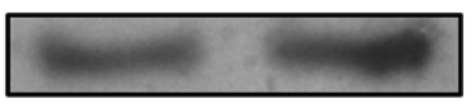

GAPDH
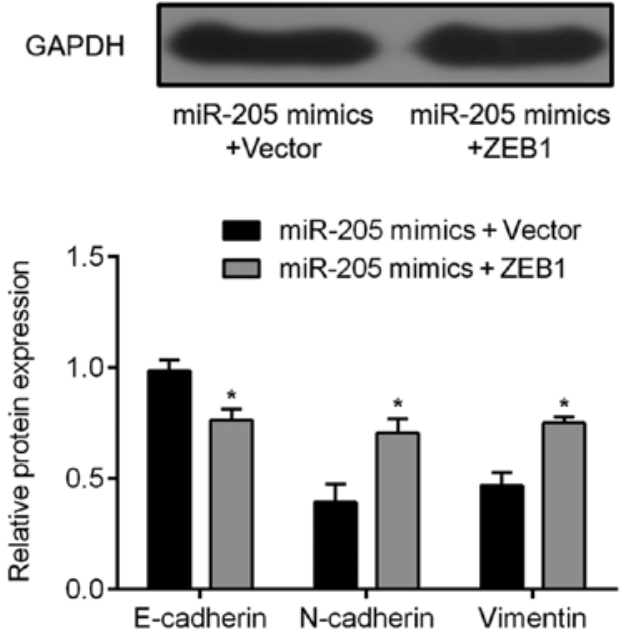

Figure 9. ZEB1 overexpression partially reverses miR-205-mediated EMT. (A and B) Relative expression of E-cadherin, N-cadherin, and vimentin mRNA in glioma cells. (C and D) Western blots showing the reversion of EMT markers in miR-205 mimic-treated SHG-44 or A172 cells after overexpression of ZEB1. ${ }^{*} \mathrm{P}<0.05$ vs. miR-205 mimics + vector group.

suggested that ZEB1 is a direct downstream target of miR-205. Subsequent investigation found that enforced expression of miR-205 could promote Akt/mTOR activation, by targeting ZEB1. Akt controls multiple biological processes including cell proliferation, differentiation, apoptosis, and tumorigenesis (37). miR-200c has been reported to enhance non-small cell lung cancer cell sensitivity in response to gefitinib and induce apoptosis through the PI3K/Akt signaling pathway via targeting ZEB1 (38). Another study suggested that miR-205 promotes EMT in nasopharyngeal carcinoma cells via the regulation of PTEN and Akt signaling (39). Accordingly, we found miR-205 moderated cell metastasis and EMT through activating the Akt/mTOR signaling pathway by targeting ZEB1 in GBM cell lines. Furthermore, we found that overexpression of ZEB1 could partially abolish miR-205-mediated suppression of migration and invasion of these cells.

ZEB1 is a transcriptional factor that was originally shown to suppress interleukin (IL)-2 gene expression (40). Numerous studies have reported that ZEB1 is expressed in a variety of cancers and is an important regulator of EMT, which plays an important role in cancer metastasis (41-43). Qu et al indicated that miR-33b suppresses tumor cell growth and EMT via directly targeting ZEB1 (44), and Sun et al found that miR-431 suppresses ZEB1-induced EMT in hepatocellular carcinoma (45). Moreover, a recent study reported that overexpression of ZEB1 in GBM could also induce EMT, which was regulated by miR-590-3p (46). However, this finding does not clarify the potential signaling pathway of ZEB1-induced EMT. In the present study, we focused on the importance of the Akt signaling pathway and hypothesized that this pathway underlies the function of ZEB1 in EMT. Furthermore, our in vitro studies suggested ZEB1 might regulate EMT in GBM via the Akt/mTOR signaling pathway.

In conclusion, our integrated approach demonstrates the biological functions of miR-205 in GBM. We also show that overexpression of miR-205 downregulates ZEB1, inhibits GBM cell migration and invasion, and prevents EMT in GBM cells via regulation of the Akt/mTOR signaling pathway, which has important implications for further understanding the mechanisms involved in modulating tumorigenesis in GBM. 


\section{Acknowledgements}

This study was supported by the National Natural Science Foundation of China (nos. 81703011, 81272774 and 81572497) and the Science Foundation of Guangzhou Women and Children's Medical Center (nos. 5001-3001023 and 5001-2150010).

\section{References}

1. Wen PY and Kesari S: Malignant gliomas in adults. N Engl J Med 359: 492-507, 2008

2. Cancer Genome Atlas Research Network: Comprehensive genomic characterization defines human glioblastoma genes and core pathways. Nature 455: 1061-1068, 2008.

3. Dai C, Lv S, Shi R, Ding J, Zhong X, Song H, Ma X, Fan J, Sun B, Wang R, et al: Nuclear protein $\mathrm{C} 23$ on the cell surface plays an important role in activation of CXCR4 signaling in glioblastoma Mol Neurobiol 52: 1521-1526, 2015.

4. Janga SC and Vallabhaneni S: MicroRNAs as post-transcriptional machines and their interplay with cellular networks. Adv Exp Med Biol 722: 59-74, 2011.

5. Ong CA, Lao-Sirieix P and Fitzgerald RC: Biomarkers in Barrett's esophagus and esophageal adenocarcinoma: Predictors of progression and prognosis. World J Gastroenterol 16: 5669-5681, 2010.

6. Du M, Shi D, Yuan L, Li P, Chu H, Qin C, Yin C, Zhang Z and Wang M: Circulating miR-497 and miR-663b in plasma are potential novel biomarkers for bladder cancer. Sci Rep 5: 10437 , 2015.

7. Lu J, Getz G, Miska EA, Alvarez-Saavedra E, Lamb J, Peck D, Sweet-Cordero A, Ebert BL, Mak RH, Ferrando AA, et al: MicroRNA expression profiles classify human cancers. Nature 435: 834-838, 2005

8. Liu X, Lei Q, Yu Z, Xu G, Tang H, Wang W, Wang Z, Li G and $\mathrm{Wu}$ M: MiR-101 reverses the hypomethylation of the LMO3 promoter in glioma cells. Oncotarget 6: 7930-7943, 2015.

9. She X, Yu Z, Cui Y, Lei Q, Wang Z, Xu G, Xiang J, Wu M and Li G: miR-128 and miR-149 enhance the chemosensitivity of temozolomide by Rap1B-mediated cytoskeletal remodeling in glioblastoma. Oncol Rep 32: 957-964, 2014.

10. Tang H, Liu X, Wang Z, She X, Zeng X, Deng M, Liao Q, Guo X, Wang $\mathrm{R}, \mathrm{Li} \mathrm{X}$, et al: Interaction of hsa-miR-381 and glioma suppressor LRRC4 is involved in glioma growth. Brain Res 1390: 21-32, 2011

11. Song S, Fajol A, Tu X, Ren B and Shi S: miR-204 suppresses the development and progression of human glioblastoma by targeting ATF2. Oncotarget 7: 70058-70065, 2016

12. Song H, Zhang Y, Liu N, Wan C, Zhang D, Zhao S, Kong Y and Yuan L: miR-92b regulates glioma cells proliferation, migration, invasion, and apoptosis via PTEN/Akt signaling pathway. J Physiol Biochem 72: 201-211, 2016.

13. Li S, Zeng A, Hu Q, Yan W, Liu Y and You Y: miR-423-5p contributes to a malignant phenotype and temozolomide chemoresistance in glioblastomas. Neuro-oncol 19: 55-65, 2017.

14. Song $\mathrm{H}$ and Bu G: MicroRNA-205 inhibits tumor cell migration through down-regulating the expression of the LDL receptorrelated protein 1. Biochem Biophys Res Commun 388: 400-405, 2009.

15. Hou SX, Ding BJ, Li HZ, Wang L, Xia F, Du F, Liu LJ, Liu YH, Liu XD, Jia JF, et al: Identification of microRNA-205 as a potential prognostic indicator for human glioma. J Clin Neurosci 20: 933-937, 2013

16. Boll K, Reiche K, Kasack K, Mörbt N, Kretzschmar AK, Tomm JM, Verhaegh G, Schalken J, von Bergen M, Horn F, et al MiR-130a, miR-203 and miR-205 jointly repress key oncogenic pathways and are downregulated in prostate carcinoma. Oncogene 32: 277-285, 2013

17. Liu S, Tetzlaff MT, Liu A, Liegl-Atzwanger B, Guo J and Xu X: Loss of microRNA-205 expression is associated with melanoma progression. Lab Invest 92: 1084-1096, 2012.

18. Thiery JP: Epithelial-mesenchymal transitions in tumour progression. Nat Rev Cancer 2: 442-454, 2002.

19. Liu H, Wang H, Liu X and Yu T: miR-1271 inhibits migration, invasion and epithelial-mesenchymal transition by targeting ZEB1 and TWIST1 in pancreatic cancer cells. Biochem Biophys Res Commun 472: 346-352, 2016
20. Siebzehnrubl FA, Silver DJ, Tugertimur B, Deleyrolle LP, Siebzehnrubl D, Sarkisian MR, Devers KG, Yachnis AT, Kupper MD, Neal D, et al: The ZEB1 pathway links glioblastoma initiation, invasion and chemoresistance. EMBO Mol Med 5: 1196-1212, 2013

21. Aigner K, Dampier B, Descovich L, Mikula M, Sultan A, Schreiber M, Mikulits W, Brabletz T, Strand D, Obrist P, et al: The transcription factor ZEB1 (deltaEF1) promotes tumour cell dedifferentiation by repressing master regulators of epithelial polarity. Oncogene 26: 6979-6988, 2007.

22. Louis DN, Ohgaki H, Wiestler OD, Cavenee WK, Burger PC, Jouvet A, Scheithauer BW and Kleihues P: The 2007 WHO classification of tumours of the central nervous system. Acta Neuropathol 114: 97-109, 2007.

23. Sun X, Li Y, Yu J, Pei H, Luo P and Zhang J: miR-128 modulates chemosensitivity and invasion of prostate cancer cells through targeting ZEB1. Jpn J Clin Oncol 45: 474-482, 2015.

24. Zhang H, Cao H, Xu D and Zhu K: MicroRNA-92a promotes metastasis of nasopharyngeal carcinoma by targeting the PTEN/ AKT pathway. Onco Targets Ther 9: 3579-3588, 2016.

25. Guo K, Zheng S, Xu Y, Xu A, Chen B and Wen Y: Loss of miR-26a-5p promotes proliferation, migration, and invasion in prostate cancer through negatively regulating SERBP1. Tumour Biol 37: 12843-12854, 2016.

26. Wu S, Huang S, Ding J, Zhao Y, Liang L, Liu T, Zhan R and He X: Multiple microRNAs modulate p21Cip1/Waf1 expression by directly targeting its $3^{\prime}$ untranslated region. Oncogene 29: 2302-2308, 2010

27. LeBlanc VC and Morin P Jr: Exploring miRNA-associated signatures with diagnostic relevance in glioblastoma multiforme and breast cancer patients. J Clin Med 4: 1612-1630, 2015.

28. Shea A, Harish V, Afzal Z, Chijioke J, Kedir H, Dusmatova S, Roy A, Ramalinga M, Harris B, Blancato J, et al: MicroRNAs in glioblastoma multiforme pathogenesis and therapeutics. Cancer Med 5: 1917-1946, 2016

29. Luo JW, Wang X, Yang Y and Mao Q: Role of micro-RNA (miRNA) in pathogenesis of glioblastoma. Eur Rev Med Pharmacol Sci 19: 1630-1639, 2015.

30. Wang H, Tao T, Yan W, Feng Y, Wang Y, Cai J, You Y, Jiang T and Jiang C: Upregulation of miR-181s reverses mesenchymal transition by targeting KPNA4 in glioblastoma. Sci Rep 5: 13072, 2015.

31. Yan Y,Wu J, Wu M, Xia Y, Tang W and Liao Z: MiR-143 suppresses the epithelial-mesenchymal transition of spinal glioblastoma through down-regulation of ERK5. Oncotarget: doi: 10.18632/ oncotarget.12977.

32. Puhr M, Hoefer J, Schäfer G, Erb HH, Oh SJ, Klocker H, Heidegger I, Neuwirt $\mathrm{H}$ and Culig Z: Epithelial-to-mesenchymal transition leads to docetaxel resistance in prostate cancer and is mediated by reduced expression of miR-200c and miR-205. Am J Pathol 181: 2188-2201, 2012.

33. Wang L, Shan M, Liu Y, Yang F, Qi H, Zhou L, Qiu L and Li Y: miR-205 suppresses the proliferative and migratory capacity of human osteosarcoma Mg-63 cells by targeting VEGFA. Onco Targets Ther 8: 2635-2642, 2015.

34. Gregory PA, Bert AG, Paterson EL, Barry SC, Tsykin A, Farshid G, Vadas MA, Khew-Goodall Y and Goodall GJ: The miR-200 family and miR-205 regulate epithelial to mesenchymal transition by targeting ZEB1 and SIP1. Nat Cell Biol 10: 593-601, 2008.

35. Matsushima K, Isomoto $\mathrm{H}$, Yamaguchi $\mathrm{N}$, Inoue $\mathrm{N}$, Machida H, Nakayama T, Hayashi T, Kunizaki M, Hidaka S, Nagayasu T, et al: MiRNA-205 modulates cellular invasion and migration via regulating zinc finger E-box binding homeobox 2 expression in esophageal squamous cell carcinoma cells. J Transl Med 9: 30, 2011 .

36. Xu C, Li M, Zhang L, Bi Y, Wang P, Li J and Jiang X: MicroRNA-205 suppresses the invasion and epithelial-mesenchymal transition of human gastric cancer cells. Mol Med Rep 13: 4767-4773, 2016

37. Manning BD and Cantley LC: AKT/PKB signaling: Navigating downstream. Cell 129: 1261-1274, 2007.

38. Zhou G, Zhang F, Guo Y, Huang J, Xie Y, Yue S, Chen M, Jiang H and Li M: miR-200c enhances sensitivity of drug-resistant non-small cell lung cancer to gefitinib by suppression of PI3K/ Akt signaling pathway and inhibites cell migration via targeting ZEB1. Biomed Pharmacother 85: 113-119, 2017.

39. Mao Y, Wu S, Zhao R and Deng Q: MiR-205 promotes proliferation, migration and invasion of nasopharyngeal carcinoma cells by activation of AKT signalling. J Int Med Res 44: 231-240, 2016. 
40. Williams TM, Moolten D, Burlein J, Romano J, Bhaerman R, Godillot A, Mellon M, Rauscher FJ III and Kant JA: Identification of a zinc finger protein that inhibits IL-2 gene expression. Science 254: 1791-1794, 1991.

41. Wang Y, Wen M, Kwon Y, Xu Y, Liu Y, Zhang P, He X, Wang Q, Huang Y, Jen KY, et al: CUL4A induces epithelial-mesenchymal transition and promotes cancer metastasis by regulating ZEB1 expression. Cancer Res 74: 520-531, 2014.

42. Ohashi S, Natsuizaka M, Naganuma S, Kagawa S, Kimura S, Itoh H, Kalman RA, Nakagawa M, Darling DS, Basu D, et al: A NOTCH3-mediated squamous cell differentiation program limits expansion of EMT-competent cells that express the ZEB transcription factors. Cancer Res 71: 6836-6847, 2011.

43. Eger A, Aigner K, Sonderegger S, Dampier B, Oehler S, Schreiber M, Berx G, Cano A, Beug H and Foisner R: DeltaEF1 is a transcriptional repressor of E-cadherin and regulates epithelial plasticity in breast cancer cells. Oncogene 24: 2375-2385, 2005.
44. Qu J, Li M, An J, Zhao B, Zhong W, Gu Q, Cao L, Yang H and Hu C: MicroRNA-33b inhibits lung adenocarcinoma cell growth, invasion, and epithelial-mesenchymal transition by suppressing $\mathrm{Wnt} / \beta$-catenin/ZEB1 signaling. Int J Oncol 47: 2141-2152, 2015 .

45. Sun K, Zeng T, Huang D, Liu Z, Huang S, Liu J and Qu Z: MicroRNA-431 inhibits migration and invasion of hepatocellular carcinoma cells by targeting the ZEB1-mediated epithelial-mensenchymal transition. FEBS Open Bio 5: 900-907, 2015

46. Pang H, Zheng Y, Zhao Y, Xiu X and Wang J: miR-590-3p suppresses cancer cell migration, invasion and epithelial-mesenchymal transition in glioblastoma multiforme by targeting ZEB1 and ZEB2. Biochem Biophys Res Commun 468: 739-745, 2015. 